\title{
Addressing the Common Pathway Underlying Hypertension and Diabetes in People Who Are Obese by Maximizing Health: The Ultimate Knowledge Translation Gap
}

\author{
Elizabeth Dean, ${ }^{1}$ Constantina Lomi, ${ }^{2}$ Selma Bruno, ${ }^{3}$ Hamzeh Awad, ${ }^{4}$ \\ and Grainne O'Donoghue ${ }^{5}$ \\ ${ }^{1}$ Department of Physical Therapy, Faculty of Medicine, University of British Columbia, Vancouver, BC, Canada V6T $1 Z 3$ \\ ${ }^{2}$ Department of Physiotherapy, Akmi Metropolitan College, 15125 Athens, Greece \\ ${ }^{3}$ Departamento de Fisioterapia, Universidade Federal do Rio Grande do Norte, 59072-970 Natal, RN, Brazil \\ ${ }^{4}$ Department of Prevention and Care of Diabetes, Faculty of Medicine, Dresden University of Technology and \\ Ludwig-Maximilian University, 80336 Munich, Germany \\ ${ }^{5}$ Department of Physiotherapy, School of Public Health, Physiotherapy, and Population Science, University College Dublin, \\ Dublin 4, Ireland
}

Correspondence should be addressed to Elizabeth Dean, elizabeth.dean@ubc.ca

Received 17 December 2010; Accepted 11 January 2011

Academic Editor: Kazuko Masuo

Copyright (C) 2011 Elizabeth Dean et al. This is an open access article distributed under the Creative Commons Attribution License, which permits unrestricted use, distribution, and reproduction in any medium, provided the original work is properly cited.

\begin{abstract}
In accordance with the WHO definition of health, this article examines the alarming discord between the epidemiology of hypertension, type 2 diabetes mellitus (T2DM), and obesity and the low profile of noninvasive (nondrug) compared with invasive (drug) interventions with respect to their prevention, reversal and management. Herein lies the ultimate knowledge translation gap and challenge in 21 st century health care. Although lifestyle modification has long appeared in guidelines for medically managing these conditions, this evidence-based strategy is seldom implemented as rigorously as drug prescription. Biomedicine focuses largely on reducing signs and symptoms; the effects of the problem rather than the problem. This article highlights the evidencebased rationale supporting prioritizing the underlying causes and contributing factors for hypertension and T2DM, and, in turn, obesity. We argue that a primary focus on maximizing health could eliminate all three conditions, at best, or, at worst, minimize their severity, complications, and medication needs. To enable such knowledge translation and maximizing health outcome, the health care community needs to practice as an integrated team, and address barriers to effecting maximal health in all patients. Addressing the ultimate knowledge translation gap, by aligning the health care paradigm to 21 st century needs, would constitute a major advance.
\end{abstract}

\section{Introduction}

In accordance with the WHO definition of health and its conceptualization of health and disability (International Classification of Functioning, Disease, and Health) [1, 2], this article examines the alarming discord between the epidemiology of hypertension, type 2 diabetes mellitus, and obesity and the low profile of exploiting noninvasive interventions compared with invasive interventions (drugs) with respect to their prevention and reversal as well as management. Since the last half of the 20th century, lifestyle- related conditions have been among the leading causes of morbidity and premature death in middle-income and low-income countries as well as high-income countries (paralleling economic development in the former) $[3,4]$. Lifestyle-related conditions include hypertension, type 2 diabetes mellitus, obesity as well as ischemic heart disease, smoking-related conditions, stroke, and many cancers [5]. On examining the causes and contributing factors to these conditions, some common lifestyle behaviors have been unequivocally implicated. The lifestyle behaviors that are associated with or contribute to common lifestyle-related 
TABLE 1: Major modifiable risk factors for chronic lifestyle-related conditions.

\begin{tabular}{|c|c|c|c|c|c|}
\hline Risk factor & $\begin{array}{c}\text { Cardiovascular (ischemic heart } \\
\text { disease \& hypertension) and } \\
\text { peripheral vascular disease }\end{array}$ & $\begin{array}{l}\text { Chronic obstructive } \\
\text { lung disease }\end{array}$ & Stroke & $\begin{array}{l}\text { Type } 2 \text { diabetes } \\
\text { mellitus }\end{array}$ & Cancer \\
\hline \multirow[t]{2}{*}{ Smoking } & $\mathrm{X}$ & $\mathrm{X}$ & $\mathrm{X}$ & $\mathrm{X}$ & $\mathrm{X}$ \\
\hline & & & & & ( $\uparrow$ risk of all-cause cancer* $\left.{ }^{*}\right)$ \\
\hline Physical inactivity & $\mathrm{X}$ & & $\mathrm{X}$ & $\mathrm{X}$ & $\mathrm{X}$ \\
\hline Obesity & $\mathrm{X}$ & & $\mathrm{X}$ & $\mathrm{X}$ & $\mathrm{X}$ \\
\hline Nutrition & $\mathrm{X}$ & & $\mathrm{X}$ & $\mathrm{X}$ & $\mathrm{X}$ \\
\hline High blood pressure & $\mathrm{X}$ & & $\mathrm{X}$ & $\mathrm{X}$ & \\
\hline Dietary fat ${ }^{\dagger} /$ blood lipids & $\mathrm{X}$ & & $\mathrm{X}$ & $\mathrm{X}$ & $\mathrm{X}$ \\
\hline Elevated glucose levels & $\mathrm{X}$ & & $\mathrm{X}$ & $\mathrm{X}$ & $\mathrm{X}$ \\
\hline Alcohol $^{\ddagger}$ & $\mathrm{X}$ & & $?$ & $\mathrm{X}$ & $\mathrm{X}$ \\
\hline
\end{tabular}

* Smoking is not only related to cancer of the nose, mouth, airways, and lungs, but smoking also increases the risk of all-cause cancer.

† Partially saturated, saturated, and trans fats are the most injurious to health.

${ }^{\ddagger}$ Alcohol can be protective in moderate quantities, red wine in particular.

Sources: references [10-12].

conditions are shown in Table 1. This evidence supports that lifestyle-related conditions are largely multifactorial rather than resulting from one cause. When an individual is diagnosed with a lifestyle-related condition, the probability that he or she has more than one unhealthy lifestyle behavior is high, for example, smokers tend to exercise less; people who watch television for many hours daily tend to be overweight compared with those who watch television less; those who are not physically active tend to eat less healthfully [6-8]. Collectively, Western lifestyle behaviors have been predicted to limit life expectancy of this generation of children as well as contribute to many years of living with one or more chronic lifestyle-related conditions [9]. Although the relationship between lifestyle and chronic conditions has been well established, addressing lifestyle and behavior change has lagged being fully integrated into contemporary health care practice.

The general purpose of this article is to enable health care practitioners to better address the ultimate knowledge translation gap in their practices, that is, the link between lifestyle behavior choices and conditions such as hypertension, type 2 diabetes mellitus, and obesity. Specifically, we identify the common pathway that may lead to hypertension and type 2 diabetes mellitus in people who are obese. We argue that addressing this common pathway in routine practice through effective multiple health behavior change can be integrated readily and has several benefits; first, potential causes rather than simply the signs and/or symptoms are addressed. Addressing the causes helps maximize the individual's health overall given the etiological commonalities of these conditions which are also related to ischemic heart disease and some cancers, and helps to minimize the potential for iatrogenic effects of the conventional biomedical management of these conditions, as well as cascade iatrogenesis (treating the side effects of the treatment for the side effects of biomedical intervention). In turn, addressing the etiological and/or contributing lifestyle- related behaviors helps to maximize health-related quality of life and, in the event the individual becomes ill or disabled, helps to maximize their medical and surgical outcomes. The cost of not addressing the potential causes of lifestylerelated conditions as a priority is unsustainable and not best practice, given the evidence and the documented effect sizes of healthy living on health-related outcomes. Finally, the barriers as well as the facilitators to multiple health behavior change being a universally accepted clinical competency across the health care professions are presented.

\section{The Common Pathway: Lifestyle-Related Behaviors}

A paradigm shift has occurred in health care priorities over the past 60 years, that is, from acute infectious disease where an individual would tend to have one offending microorganism to lifestyle-related conditions that tend to be multifactorial $[13,14]$. A reductionistic model provides a lens that looks for a problem usually a sign or symptom that can be targeted by one or more drugs. This model had some utility in the era of acute infectious disease; however, its applicability to the complexity of chronic lifestyle-related conditions appears limited given the increasing prevalence of hypertension, type 2 diabetes mellitus, and obesity. Through the lens of a noninvasive practitioner who exploits nondrug and nonsurgical interventions, the signs and symptoms of chronic lifestyle-related conditions are viewed largely as effects, and these need to be remediated by modifying the causes or contributing factors related to lifestyle. Medication does not always ensure effective control of blood pressure or blood sugar when left to real-world nonlaboratory contingencies. Further, a patient may believe that medication can control blood pressure or blood sugar better than they can and that this will offset the effect of poor lifestyle choices. 
New terms such as obesogenic and diabetogenic have emerged in the common vernacular to describe Western society. Since World War II, economic growth has been associated with the evolution of convenience foods and the fast food industry (associated with mass-produced food products that are high in fat and sugar, hence, calories, and salt, preservatives, flavor enhances, colorants, and other additives). Packaged and easily prepared foods are associated with less nutritional value and additives to enhance shelf life and appearance. Good nutrition including a range of micro and macro nutrients is needed for optimal health and wellbeing, healing and repair, immunity, as well as energy. The Western diet is suboptimal nutritionally and has been described as monotonous and unbalanced. Compared with dietary regimes such as Mediterranean and Asian diets, the typical Western diet contributes to the high prevalence of ischemic heart disease, hypertension, stroke, and cancer as well as type 2 diabetes mellitus, and overweight and obesity $[4,14]$. Further, some authorities have argued that lobbyists have influenced the nutrition guidelines that in previous years endorsed excessive saturated fat, sugar, meat consumption, and refined carbohydrates [15-17]. In turn, it is adherence to these guidelines that has contributed to lifestyle-related conditions in recent decades.

An individual who is obese with diagnoses of hypertension and type 2 diabetes mellitus often has a profile reflecting prolonged unhealthy lifestyle practices, potentially since childhood, which eventually become preferences. As a child, he or she may have been exposed to a diet higher than recommended in salt, sugar, refined foods, and fat (particularly saturated fat) which developed personal preferences early in life. In addition, comparable to smoking, children mimic the activity patterns of their families particularly their guardians or parents [18]. Similarly, other behaviors are likely to be mimicked, for example, hours of daily television viewing (often associated with snacking calorie-dense nonnutritious foods), or computer or video game use. Evidence over the past decade shows that the effects of sedentary living are distinct from low levels of physical activity $[19,20]$. Prolonged periods of being sedentary are associated with health risk even if an individual exercises aerobically the recommended three times a week at a moderate intensity for 30 minutes. Like obesity, hypertension and type 2 diabetes mellitus develop over many years with prolonged exposure to factors that adversely affect vascular resistance and glucose metabolism, specifically, insulin sensitivity and resistance. Conversely, assuming healthy dietary habits (the Dash diet and diabetic diet which share common elements), less sitting coupled with regular daily physical activity, along with smoking cessation would do much to eliminate high blood pressure and type 2 diabetes mellitus in many patients, or at least reduce their manifestations and in turn their dire consequences.

Finally, systemic low-level inflammation has been identified as a common denominator in the chronic lifestylerelated conditions. Such inflammation has been associated with the Western diet and inactivity $[21,22]$. Maximizing healthy lifestyle choices needs to be a focus of healthy soci- eties to reduce the injurious effects of chronic inflammation even if considered low grade.

\section{Effectiveness of Multiple Health Behavior Change}

Health promotion practice needs to be integrated into the practices of contemporary health care professionals given the prevalence of lifestyle-related conditions and their being the leading causes of morbidity, disability, and premature death [23]. Based on the substantial body of evidence supporting the effectiveness of healthy living including not smoking, optimal weight and nutrition, and regular physical activity, new paradigms of practice are being called for that promote healthy living as a primary intervention. Recently, a paradigm of practice aligned with epidemiological need and the body of knowledge supporting the effectiveness of noninvasive interventions has been advanced for physical therapists in the 21st century [24]. Physical therapists are the quintessential established noninvasive health care professionals that need to take a lead in advancing the exploitation of noninvasive interventions in the prevention, reversal, and management of chronic lifestyle-related conditions. They serve as an example of a key health care profession capable of practicing shoulder to shoulder with physicians and surgeons to promote the best noninvasive approaches for a given patient.

The integration of health promotion into the practices of health professionals would help bridge the ultimate knowledge translation gap between the knowledge and power of healthy living, and the prevalence of lifestyle-related conditions. Health promotion practice, however, may be undervalued in that its outcomes are more challenging to identify than ill health outcomes. Health promotion practice raises the question of how much behavior change is needed to translate into better health. Studies are now addressing this critical question. In sum, not much change is needed. Excessive blood pressure can decrease with small amounts of weight loss [25] with commensurate reduction in health risk. In a recent study of over 23,000 people between 35 and 65 years old, Ford and colleagues [26] reported that over an eight-year period, people who did not smoke, had a body mass index of less than 30 , were physically active for a minimum of 3.5 hours a week, and followed healthy nutritional principles, had a $78 \%$ lower risk of developing a chronic condition. Specifically, the risk of type 2 diabetes mellitus was reduced by $93 \%$, myocardial infarction by $81 \%$, stroke by $50 \%$, and cancer by $36 \%$. Even if not all four health factors were present, risk of developing a chronic lifestyle-related condition decreased commensurate with an increase in the number of positive lifestyle factors. Not only can few drugs replicate these effect sizes, but the absence of side effects, and the cost effectiveness of healthy living, not to mention ethical issues, are compelling reasons for exploiting healthy living maximally and minimizing ill health so that those individuals who really need this expensive care can receive it in a timely manner with the potential for the best outcomes. This warrants being done systematically 
and always in conjunction with medical interventions as outcomes overall will likely be superior.

\section{Integrating Multiple Health Behavior Change as a Priority into Practice}

That the physician can assume full responsibility for holistic patient management is neither realistic nor feasible. The healthcare environment has changed radically since the era of infectious disease when there was a clear microorganism and a well-defined pharmacologic intervention that could be simply identified and managed. Infectious conditions tend to have similar profiles on presentations. Lifestylerelated conditions including those that affect the vasculature however fit this model less well. Their etiologies and manifestations are complex and multisystemic, and patients present differently despite some commonalities in the etiological lifestyle contributing factors. The etiologic health behaviors that underlie the causative factors need to be teased out systematically to address them maximally in every individual, including children who are exhibiting the risk factors of lifestyle-related conditions (e.g., high blood pressure, abnormal cholesterol, triglycerides, and blood glucose, and excess body weight and abnormal mass distribution, and deconditioning) [27]. In mainstream health care practice this century, vital signs have become reflective of lifestylerelated conditions. In adults, healthy blood pressure is ideally below 120/80 mm Hg [28], body mass index between 18.5 and 24.9 [29], and waist to hip ratio less than 0.85 for women and 0.90 for men [30]. To maximize such outcomes, the current healthcare environment calls for an integrated interprofesssional approach [31] to improve the effectiveness and efficiency of care.

Of the established health care professions, physical therapy is the leading noninvasive health care profession [32]. For almost 100 years, physical therapy has been associated with noninvasive interventions, specifically, health education and exercise to promote health, prevent disease, and manage conditions. The quintessential clinical competency in the 21 st century of health care providers including physical therapists has been described as effecting multiple health behavior change $[32,33]$. Changes in diet and physical activity levels can have profound effects on health outcomes such as reducing blood pressure and reducing blood sugar within days or weeks, and reducing weight over time, see recent reviews $[32,33]$. The success of these simple interventions rests with the quality of the education from the relevant health care providers, as well as patient adherence and systematic followup. This suggests that health assessment and health education warrant being primary clinical competencies of health care practitioners in the 21st century regardless of the patient's primary complaint or problem. Although physicians are primarily qualified as invasive practitioners specializing in the optimal use of drugs and surgery, it behooves them to practice alongside noninvasive practitioners to best address a patient's health issues and maximize the effects of drugs or surgery. Physicians need to know when to refer to other health care practitioners; this is a collegial synergistic approach that effects the best outcome, short and long term, for the patient.

Although health education and lifestyle-related changes are mentioned in established guidelines for the management of all three conditions, namely, hypertension, type 2 diabetes mellitus, and obesity, seldom are they addressed as one entity having a common pathway which is highly modifiable through health behavior change. The literature on health behavior change, however, remains largely to be integrated into mainstream health care [34].

Western foods often have high sodium or salt content. In addition, foods high in sodium are typically associated with convenience and suboptimal nutrition, hence, are obesogenic and diabetogenic. In addition, the benefits of the Dash diet to stop hypertension $[35,36]$ have been well known for almost two decades, it supports the general health benefits associated with dietary regimens that are high in multigrains, vegetables, and are low in fat and sugar. Such a dietary regimen is optimal for the health of people in general, not only those with hypertension $[37,38]$. The wide range of unhealthy food options despite the public's knowledge about healthy lifestyles adds to the challenge of promoting healthful eating. One prime example is salt consumption. An overriding simple solution is restricting added salt to foods. A one-third reduction of salt intake by the average American (from $3400 \mathrm{mg}$ to $2300 \mathrm{mg}$ daily) would reduce cases of hypertension, the second leading causes of death in the United States, by 11 million, and lower health care costs by $\$ 17.8$ billion [39].

Smoking tobacco is associated with the inhalation of nicotine, a well-known vasoconstrictor, thus, smokers are prone to hypertension, ischemic heart disease, and stroke which has been well documented for many years [40]. Smokers also have poorer health behaviors than nonsmokers including poorer diets and inactivity [41]. In North America, smoking reduction over the past 40 years largely paralleled strict legislative controls on the selling and marketing of tobacco products, and increased taxation. More recently, tobacco smoking has been restricted in many countries with national policies and city by-laws prohibiting smoking in public places. Canada has been a leader in this area [42, 43]. At the clinical level, even brief advice by a health care provider helps smokers eventually quit [44].

The lack of physical activity has been described as the most critical disease of the past and present centuries in highincome countries [45]. Inactivity has not only been directly associated with hypertension, type 2 diabetes mellitus, and obesity, but it doubles their risks.

Given the interrelationships among lifestyle behaviors and the triad of hypertension, type 2 diabetes mellitus, and overweight and obesity, a reductionistic biomedical approach (a specific medication is prescribed for hypertension or type 2 diabetes mellitus) will likely be suboptimal in addressing their common pathway, and effecting lifelong health and wellbeing. In addition, the patient may be less likely to appreciate the common pathway if conditions are compartmentalized in this manner.

The health care practitioners of the 21st century need to have clinical competencies related to multiple health 
behavior change. They need the capacity to motivate people to sustain lifelong health behavior change $[34,46]$, to assess readiness to change and gauge health behavior change strategies to a person's needs at a given time [47], to engage the family and take advantage of social contagion effects of positive health behaviors [48], and serve as a role model with positive attitudes toward maximal health [49]. In fact, patients are receptive to advice from health care professionals that they perceive as supportive and nonjudgmental [50,51].

To change the course of lifestyle-related conditions, effective interprofessional team work is needed. The composition of the team that needed in the 21st century extends beyond the traditional team of physician, nurse, and pharmacist. It needs to include those who specialize in noninvasive, that is, nondrug and nonsurgical, interventions, including physical therapists, nutritionists, and counselors.

A new approach in contemporary health care is improved sharing of skills, expertise, and competencies. In addition, such an approach includes triaging patients to balance the need for noninvasive and invasive strategies for prevention, reversal, and management. The goal is to wean a patient off medications as much as possible after healthy living has had an opportunity to have a maximal effect.

Many authorities would concur that health care costs reflect doctor and hospital care, and the cost of medication [52]. This model of care is not sustainable and raises some serious ethical questions given that the evidence supports that healthy living [26] can reduce the risk of type 2 diabetes mellitus by $93 \%$, ischemic heart disease by $73 \%$, stroke by $50 \%$, and cancer by $30 \%$.

Maximizing health promotion in daily medical practice has the potential for increasing the threshold for chronic lifestyle-related conditions and reducing their rate of progression. If the end of life is viewed as the convergence of these two points, the end of life could be shifted such that premature death is offset with reduced end of life morbidity and disability (Figure 1). Health behaviors and outcomes can easily be tracked over time to provide both the practitioner and the patient with feedback about the patient's health behaviors and where the practitioner needs to focus further or refer the patient to another profession. An example of an insert to a chart to track health behavior change and outcomes appears in Table 2. Such a log enables the practitioner to target specific lifestyle changes needed and $\log$ lifestyle recommendations more effectively, engage other health care professionals, or both.

\section{Revisiting Conservative Approaches: Ethical Issues}

Access to high-tech medicine and drugs are equated with quality health care. From the noninvasive practitioner's perspective, one would argue that the exploitation of healthy living would help minimize the need for biomedical intervention and, if needed, would reduce the level of intervention required and enhance outcomes. In recent decades, much attention has been given to ethical practice, specifically, the right treatment for the right condition for the right

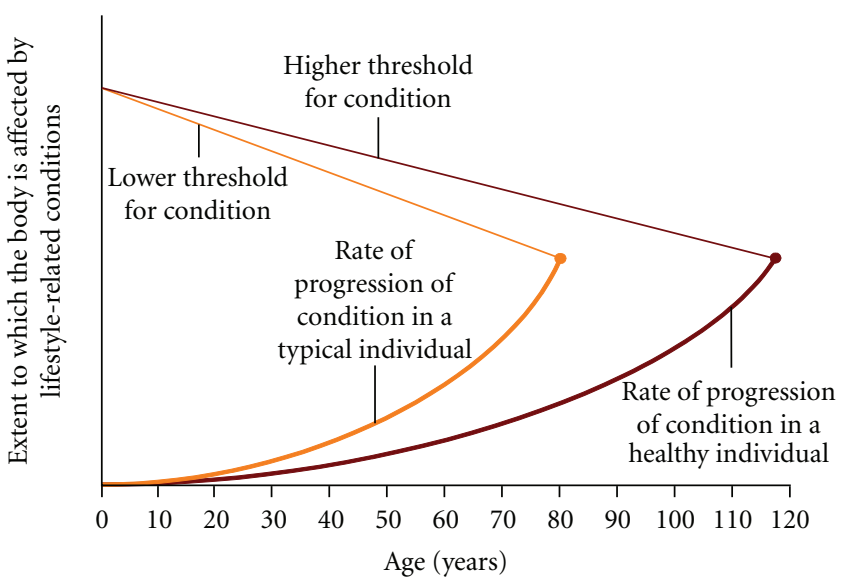

FIgURE 1: Theoretical relationship between the threshold of lifestyle-related conditions and their rate of progression over the life cycle. Horizontal axis: age. Vertical axis: extent to which the body is affected by lifestyle-related conditions. Top light line: threshold for chronic conditions with average Western lifestyle. Lower light line: rate of progression of chronic conditions with average Western lifestyle. Top dark line: threshold for chronic conditions with a healthy lifestyle. Lower dark line: rate of progression of chronic conditions with a healthy lifestyle.

patient at the right time. However, what such a philosophy does not address is "what is the right treatment?" Some base this on the results of studies that have been rated as being of high quality and published in a reputable peerreviewed journal with preferably a high impact factor. Often, however, a limitation of such studies is the lack of healthy control groups or stratification of the data in the analysis to examine the impact of good health on the outcomes of interest. It is likely that in many published studies, if this was done, that good health would trump the outcomes of drug intervention. Thus, on ethical grounds, studies related to the prevention, reversal, and management of chronic lifestyle-related conditions, need to include a healthy control group whenever feasible and appropriate, or analyze the data stratified-based indices of good health and health behaviors.

In a civil society, no patient should be denied treatment when needed. However, the invasive versus noninvasive balance needs to be addressed to establish the best treatment for a given patient. Most health care professionals would embrace the Hippocratic tenets of "first do no harm" and "the function of protecting and developing health must rank even above that of restoring it when it is impaired"; however, the practice of these tenets remains to be fully integrated into team-based health care practice. Some authorities have argued that health care is being influenced by corporate interests that are focused on the creation of disorders for which unique and expensive drugs are needed [53]. The power of pharmaceutical companies in directing an illness care versus health care agenda could seriously undermine the outcomes of noninvasive practitioners, for example, given their outcomes require long-term motivation, engagement, participation, commitment by the patient to effect lifelong health, and systematic followups. 
TABLE 2: Monitoring multiple health behavior change over time: short-form template for assessing and evaluating behaviors associated with chronic lifestyle-related conditions.

\begin{tabular}{|c|c|c|c|}
\hline Lifestyle choices and behaviors & $\begin{array}{l}\text { Initial assessment } \\
\text { date }\end{array}$ & $\begin{array}{l}\text { Followup } \\
\text { date }\end{array}$ & $\begin{array}{l}\text { Followup } \\
\text { date }\end{array}$ \\
\hline \multicolumn{4}{|l|}{ Smoking status } \\
\hline \multicolumn{4}{|l|}{ Nonsmoker or continuing not to smoke } \\
\hline \multicolumn{4}{|l|}{ Smoking (cigarettes per day) } \\
\hline \multicolumn{4}{|l|}{ Nutritional Status } \\
\hline \multicolumn{4}{|l|}{ Processed foods (e.g., deli meats) } \\
\hline \multicolumn{4}{|l|}{ Convenience foods (fast food) } \\
\hline \multicolumn{4}{|l|}{ Soda pop (cans) } \\
\hline \multicolumn{4}{|l|}{ For items below see daily serving size guide } \\
\hline \multicolumn{4}{|l|}{ Vegetables } \\
\hline \multicolumn{4}{|l|}{ Fruit } \\
\hline \multicolumn{4}{|l|}{ Whole grains } \\
\hline \multicolumn{4}{|l|}{ Meat (type) } \\
\hline \multicolumn{4}{|l|}{ Fish (type) } \\
\hline \multicolumn{4}{|l|}{ Milk (specify whole milk or fat reduced) } \\
\hline \multicolumn{4}{|l|}{ Cheese } \\
\hline \multicolumn{4}{|l|}{ Added sugar } \\
\hline \multicolumn{4}{|l|}{ Added salt } \\
\hline \multicolumn{4}{|l|}{ Saturated fat (animal fat, butter) } \\
\hline \multicolumn{4}{|l|}{ Unsaturated fat (vegetable oils) } \\
\hline \multicolumn{4}{|l|}{ Servings of mayo, prepared relishes, cats-up, gravy, margarine } \\
\hline \multicolumn{4}{|l|}{ Body composition } \\
\hline \multicolumn{4}{|l|}{ Weight } \\
\hline \multicolumn{4}{|l|}{ Height } \\
\hline \multicolumn{4}{|l|}{ Body mass index (weight in kg/height in $\mathrm{m}^{2}$ ) } \\
\hline \multicolumn{4}{|l|}{ Waist girth } \\
\hline \multicolumn{4}{|l|}{ Hip girth } \\
\hline \multicolumn{4}{|l|}{ Waist-to-hip ratio } \\
\hline \multicolumn{4}{|l|}{ Activity status: sedentary activity, physical activity, and structured exercise } \\
\hline \multicolumn{4}{|l|}{$\begin{array}{l}\text { Sedentary activity (daily hours television watching or in front of a computer } \\
\text { screen) }\end{array}$} \\
\hline \multicolumn{4}{|l|}{$\begin{array}{l}\text { General physical activity (general walking and getting around, taking public } \\
\text { transportation) }\end{array}$} \\
\hline $\begin{array}{l}\text { Structured exercise (e.g., yoga, tai chi, aerobic exercise such as walking, } \\
\text { swimming, jogging, cycling, and strengthening with weights or bands) }\end{array}$ & & & \\
\hline Type-intensity-duration-frequency_for how long overall (weeks or months) & & & \\
\hline Type-intensity-duration-frequency_for how long overall (weeks or months) & & & \\
\hline Type-intensity-duration-frequency_for how long overall (weeks or months) & & & \\
\hline
\end{tabular}

Finally, a physician who fails to prescribe an established medication to a patient for a given problem would come under professional scrutiny, with the potential for discipline, if the patient had an untoward event. Paradoxically, practitioners who fail to prescribe evidence-based noninvasive interventions such as health education and exercise that can prevent, in some cases reverse as well as manage chronic lifestyle-related conditions, such as hypertension and type 2 diabetes mellitus (as well as obesity), and are associated with lifelong benefits, appear not to be held to a comparable standard of accountability. This needs to change. Noninvasive practitioners who exploit health education and exercise need to be accountable for exploiting these interventions particularly in the interest of being responsive to current global health priorities. Such an approach would help augment the medical outcomes of 
physicians. This approach is philosophically consistent with both the wise tenets of Hippocrates for doing no harm and protecting health, to which most health care professionals would aspire, and health care based on the highest level of evidence.

\section{Conclusion}

Although lifestyle-related conditions such as hypertension, type 2 diabetes mellitus, and obesity have clinical distinctions, they share a common etiological pathway which contributes to their frequent coexistence. By addressing the common pathway through intensive targeted lifestyle behavior change, the reduced "signal-to-noise" in their patients' presentations would expedite their diagnoses, target their medications better, and achieve improved health outcomes with their patients. In turn, the long-term health of patients would be maximized, health care costs would be reduced, as well as the social burden of these conditions on families, communities and countries. This will best be achieved with a shoulder-to-shoulder relationship of invasive care practitioners (physicians) with noninvasive care practitioners (counselors, nutritionists, and physical therapists) to establish the optimal lifestyle program for a patient (and potentially the family) with a view to minimize need for or reliance on medication and the need for surgery in some cases.

\section{References}

[1] World Health Organization, "Definition of Health," 1984, http://www.who.int/about/definition.

[2] World Health Organization, "International Classification of Functioning, Disability and Health," 2002, http://www.sustainable-design.ie/arch/ICIDH-2PFDec-2000.pdf.

[3] World Health Organization, "Integrating prevention into health care. Fact sheet 172," 2010, http://www.who.int/mediacentre/factsheets/fs172/en/.

[4] R. Beaglehole and D. Yach, "Globalisation and the prevention and control of non-communicable disease: the neglected chronic diseases of adults," Lancet, vol. 362, no. 9387, pp. 903908, 2003.

[5] World Health Organization, "Priority noncommunicable diseases and conditions," 2010, http://www.wpro.who.int/NR/ rdonlyres/E72A001F-E6E1-4AB7-B33C-1C77F4FEF8FC/0/13 Chapter8.

[6] M. L. Neuhouser, D. L. Miller, A. R. Kristal, M. J. Barnett, and L. J. Cheskin, "Diet and exercise habits of patients with diabetes, dyslipidemia, cardiovascular disease or hypertension," Journal of the American College of Nutrition, vol. 21, no. 5, pp. 394-401, 2002.

[7] A. F. Subar, L. C. Harlan, and M. E. Mattson, "Food and nutrient intake differences between smokers and non-smokers in the US," American Journal of Public Health, vol. 80, no. 11, pp. 1323-1329, 1990.

[8] S. J. Sherman, J. S. Rose, K. Koch, C. C. Presson, and L. Chassin, "Implicit and explicit attitudes toward cigarette smoking: the effects of context and motivation," Journal of Social and Clinical Psychology, vol. 22, no. 1, pp. 13-39, 2003.
[9] S. J. Olshansky, D. J. Passaro, R. C. Hershow et al., "A potential decline in life expectancy in the United States in the 21st century," New England Journal of Medicine, vol. 352, no. 11, pp. 1138-1145, 2005.

[10] The Heart and Stroke Foundation of Canada, 2010, http:// www.heartandstroke.com/site/c.ikIQLcMWJtE/b.3479403/k .BF78/Health_Information.htm.

[11] J. C. Bradberry, "Peripheral arterial disease: pathophysiology, risk factors, and role of antithrombotic therapy," Journal of the American Pharmacists Association, vol. 44, no. 2, supplement 1, pp. S37-S44, 2004.

[12] N. Charkoudian and M. J. Joyner, "Physiologic considerations for exercise performance in women," Clinics in Chest Medicine, vol. 25, no. 2, pp. 247-255, 2004.

[13] P. M. Lantz, J. S. House, J. M. Lepkowski, D. R. Williams, R. P. Mero, and J. Chen, "Socioeconomic factors, health behaviors, and mortality: results from a nationally representative prospective study of US adults," Journal of the American Medical Association, vol. 279, no. 21, pp. 1703-1708, 1998.

[14] A. H. Mokdad, E. S. Ford, B. A. Bowman et al., "Prevalence of obesity, diabetes, and obesity-related health risk factors, 2001," Journal of the American Medical Association, vol. 289, no. 1, pp. 76-79, 2003.

[15] M. Nestle, "Food lobbies, the food pyramid, and U.S. nutrition policy," International Journal of Health Services, vol. 23, no. 3, pp. 483-496, 1993.

[16] O. Dyer, "US government rejects WHO's attempts to improve diet," British Medical Journal, vol. 328, no. 7433, p. 185, 2004.

[17] M. Nestle, “The ironic politics of obesity," Science, vol. 299, no. 5608, p. 781, 2003.

[18] S. S. Gidding, "Preventive pediatric cardiology. Tobacco, cholesterol, obesity, and physical activity," Pediatric Clinics of North America, vol. 46, no. 2, pp. 253-262, 1999.

[19] G. N. Healy, D. W. Dunstan, J. Salmon et al., "Breaks in sedentary time. Beneficial associations with metabolic risk," Diabetes Care, vol. 31, pp. 661-666, 2008.

[20] A. A. Thorp, G. N. Healy, N. Owen et al., "Deleterious associations of sitting time and television viewing time with cardiometabolic risk biomarkers," Diabetes Care, vol. 33, no. 2, pp. 327-334, 2010.

[21] H. Bruunsgaard, "Physical activity and modulation of systemic low-level inflammation," Journal of Leukocyte Biology, vol. 78, no. 4, pp. 819-835, 2005.

[22] A. P. Simopoulos, "Evolutionary aspects of diet, the omega6/omega-3 ratio and genetic variation: nutritional implications for chronic diseases," Biomedicine and Pharmacotherapy, vol. 60, no. 9, pp. 502-507, 2006.

[23] J. P. Alegrante, J. C. Perterson, C. Boutin-Foster, G. Ogedegbe, and M. E. Charleson, "Multiple health-risk behavior in a chronic disease population: what behaviors do people choose to change?" Preventive Medicine, vol. 46, pp. 247-251, 2008.

[24] E. Dean, "Physical therapy practice in the $21^{\text {st }}$ century: a new evidence-informed paradigm and implications," Physiotherapy Theory and Practice, vol. 25, no. 5-6, pp. 327-462, 2009.

[25] F. V. Costa, "Non-pharmacological treatment of hypertension in women," Journal of Hypertension, vol. 20, no. 2, pp. S57-S61, 2002.

[26] E. S. Ford, M. M. Bergmann, J. Kröger, A. Schienkiewitz, C. Weikert, and H. Boeing, "Healthy living is the best revenge: findings from the European prospective investigation into cancer and nutrition-potsdam study," Archives of Internal Medicine, vol. 169, no. 15, pp. 1355-1362, 2009. 
[27] G. S. Berenson, S. R. Srinivasan, W. Bao, W. P. Newman 3rd, R. E. Tracy, and W. A. Wattigney, "Association between multiple cardiovascular risk factors and atherosclerosis in children and young adults," New England Journal of Medicine, vol. 338, no. 23, pp. 1650-1656, 1998.

[28] American Heart Association Recommendations. High blood pressure, 2010, http://www.americanheart.org/presenter.jhtml ?identifier $=4623$.

[29] Health Canada. Body mass index, 2010, http://www.hc-sc .gc.ca/fn-an/nutrition/weights-poids/guide-ldadult/bmi chart_java-graph_imc_java-eng.php.

[30] S. Yusuf, S. Hawken, S. Ounpuu et al., "Obesity and the risk of myocardial infarction in 27000 participants from 52 countries: a case-control study," Lancet, vol. 366, no. 9497, pp. 1640-1649, 2005.

[31] P. G. Clark, "What is interprofessional health?" Journal of Interprofessional Care, vol. 7, pp. 219-220, 1993.

[32] E. Dean, "Physical therapy in the $21^{\text {st }}$ century-part 2 : evidence-based practice within the context of evidenceinformed practice," Physiotherapy Theory and Practice, vol. 25, no. 5-6, pp. 354-368, 2009.

[33] E. Dean, "Physical therapy in the $21^{\text {st }}$ century-part 1: toward practice informed by epidemiology and the crisis of lifestyle conditions," Physiotherapy Theory and Practice, vol. 25, no. 56, pp. 330-353, 2009.

[34] T. V. Achterberg, G. G. J. Huisma-De Waal, N. A. B. Ketelaar, R. A. Oostendorp, J. E. Jacobs, and H. C. H. Wolldersheim, "How to promote healthy behaviours in patients? An overviewof evidence for behaviour change techniques," Health Promotion International. In press.

[35] L. J. Appel, T. J. Moore, E. Obarzanek et al., "A clinical trial of the effects of dietary patterns on blood pressure," New England Journal of Medicine, vol. 336, no. 16, pp. 1117-1124, 1997.

[36] F. M. Sacks, E. Obarzanek, M. M. Windhauser et al., "Rationale and design of the Dietary Approaches to Stop Hypertension trial (DASH): a multicenter controlled-feeding study of dietary patterns to lower blood pressure," Annals of Epidemiology, vol. 5, no. 2, pp. 108-118, 1995.

[37] United States Department of Health and Human Services, Consumer Information Center. The food guide pyramid, 2010, http://www.usda.gov/.

[38] Health Canada. Canada's Food Guide, 2010, http://www.hcsc.gc.ca/fn-an/food-guide-aliment/indexeng.php.

[39] Report of the Institute of Medicine of the National Academy of Sciences. IOM report declares high blood pressure a neglected disease, calls for strategies to change Americans' lifestyles and diets to curb hypertension, 2010.

[40] J. E. Fielding, "Smoking: health effects and control," New England Journal of Medicine, vol. 313, no. 8, pp. 491-498, 1985.

[41] T. L. Conway and T. A. Cronan, "Smoking, exercise, and physical fitness," Preventive Medicine, vol. 21, no. 6, pp. 723734, 1992.

[42] M. Asbridge, "Public place restrictions on smoking in Canada: assessing the role of the state, media, science and public health advocacy," Social Science and Medicine, vol. 58, no. 1, pp. 1324, 2004.

[43] J. Drope and S. Glantz, "British Columbia capital regional district $100 \%$ smokefree bylaw: a successful public health campaign despite industry opposition," Tobacco Control, vol. 12, no. 3, pp. 264-268, 2003.

[44] M. E. Bodner and E. Dean, "Advice as a smoking cessation strategy: a systematic review and implications for physical therapists," Physiotherapy Theory and Practice, vol. 25, no. 56, pp. 369-407, 2009.
[45] World Health Organization. Physical inactivity leading cause of disease and disability, 2010, http://www.who.int/mediacentre/news/releases/release23/en/index.html.

[46] N. C. H. Stott and R. M. Pill, "Advise yes, dictate no'. Patients' views on health promotion in the consultation," Family Practice, vol. 7, no. 2, pp. 125-131, 1990.

[47] J. O. Prochaska and C. C. DiClemente, "Transtheoretical therapy: towards a more integrative model of change," Psychother, vol. 19, pp. 276-288, 1982.

[48] N. A. Christakis and J. H. Fowler, "The spread of obesity in a large social network over 32 years," New England Journal of Medicine, vol. 357, no. 4, pp. 370-379, 2007.

[49] M. Danzinger, "Tight white-coat syndrome: physician heal thyself," 2006, http://www.medscape.com/viewarticle/531752.

[50] R. E. Glasgow, L. M. Klesges, D. A. Dzewaltowski, S. S. Bull, and P. Estabrooks, "The future of health behavior change research: what is needed to improve translation of research into health promotion practice?" Annals of Behavioral Medicine, vol. 27, no. 1, pp. 3-12, 2004.

[51] M. W. Kreuter, S. G. Chheda, and F. C. Bull, "How does physician advice influence patient behavior? Evidence for a priming effect," Archives of Family Medicine, vol. 9, no. 5, pp. 426-433, 2000.

[52] S. Woolhandler, T. Campbell, and D. U. Himmelstein, "Costs of health care administration in the United States and Canada," New England Journal of Medicine, vol. 349, no. 8, pp. 768-775, 2003.

[53] R. Moynihan and A. Cassels, Selling Sickness. How the World's Biggest Pharmaceutical Companies are Turning us all into Patients, Greystone Books, Toronto, Canada, 2005. 


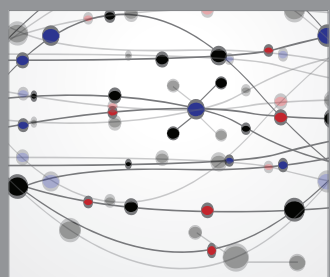

The Scientific World Journal
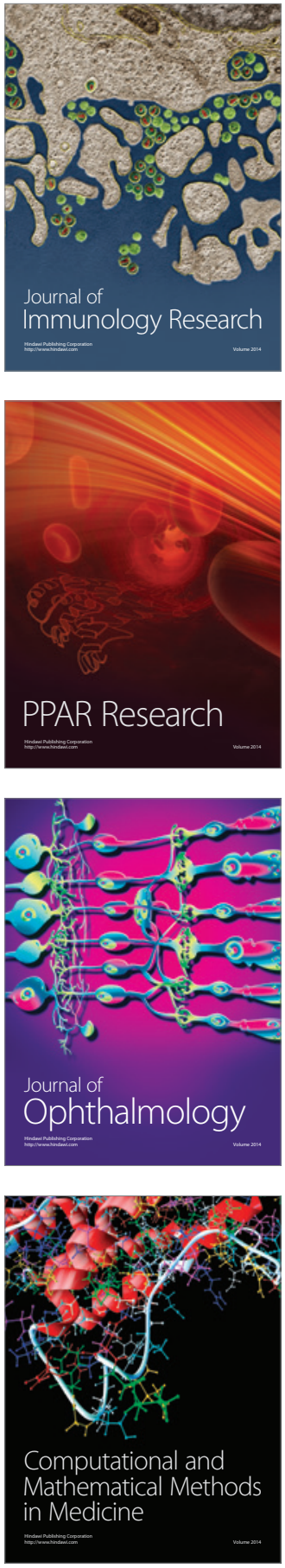

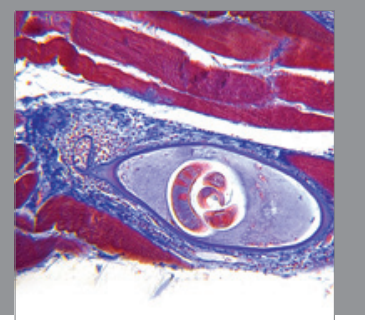

Gastroenterology

Research and Practice
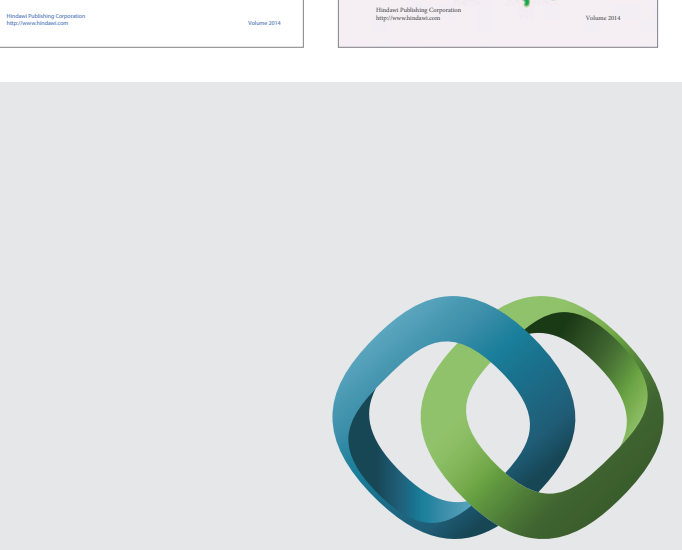

\section{Hindawi}

Submit your manuscripts at

http://www.hindawi.com
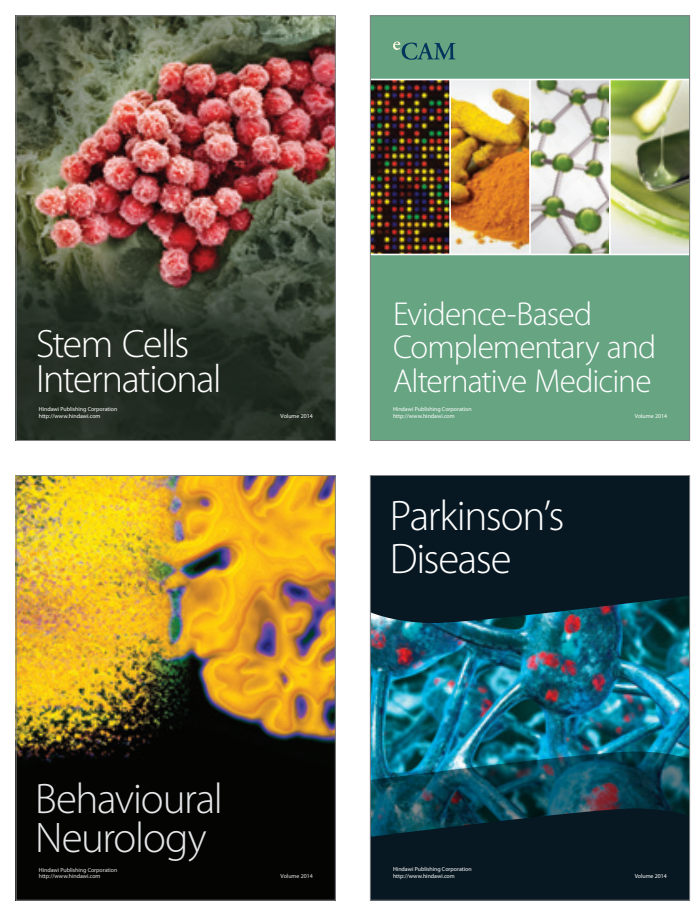

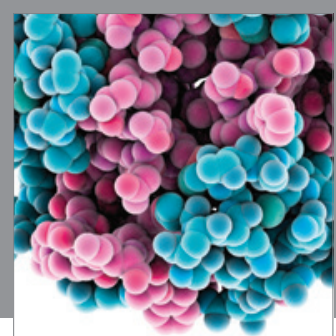

Journal of
Diabetes Research

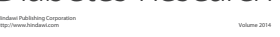

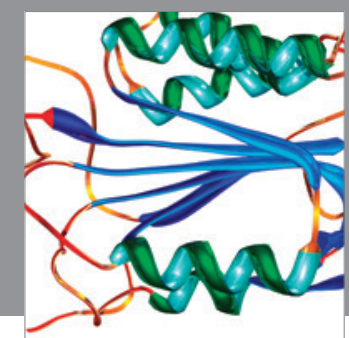

Disease Markers
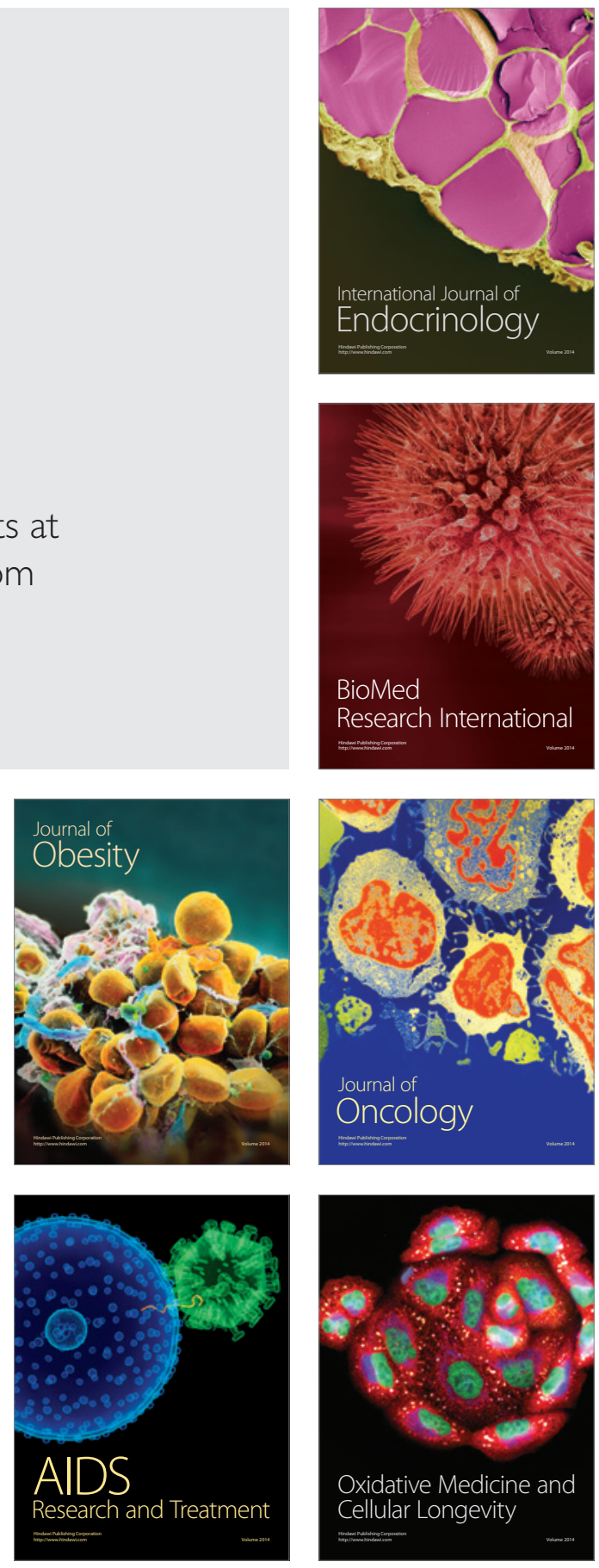